"Fl silwer ile mis hijics

Año 13.

Núm. 33

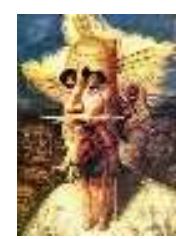

Revista de Investigación

Académica sin Frontera

ISSN: 2007-8870

http://revistainvestigacionacademicasinfrontera.com

Recibido el 5 de agosto de 2020. Dictaminado mediante arbitraje favorablemente 7 de diciembre de 2020.

Recibido el 15 de agosto de 2020 y dictaminado mediante arbitraje el 7 de diciembre de 2020

\title{
RECURSOS Y CAPACIDADES QUE INFLUYEN EN LA COMPETITIVIDAD DE UNA EMPRESA PRODUCTORA DE CALZADO EN EL ESTADO DE YUCATÁN.
}

\author{
Lic. Jeniffer Fabiola Chan Canto. Tecnológico Nacional de México/Instituto Tecnológico de \\ Mérida, jenifferchancanto@gmail.com https://orcid.org/0000-0003-3581-8809 \\ Dra. María Antonia Morales González. Tecnológico Nacional de México/Instituto \\ Tecnológico de Mérida, maria.mg@merida.tecnm.mx https://orcid.org/0000-0002-2637-0873 \\ M.C. Hermila Andrea Ulibarri Benítez. Tecnológico Nacional de México/Instituto \\ Tecnológico de Mérida, hermila.ub@merida.tecnm.mx https://orcid.org/0000-0002-9867-0330
}

\begin{abstract}
Resumen
Actualmente, las organizaciones se encuentran bajo una presión constante por mantenerse en un entorno altamente competitivo y cambiante, debido a esto, resulta de vital importancia para las empresas identificar los recursos y capacidades que impulsan o limitan su competitividad y con base en ello, implementar estrategias competitivas que permitan lograr una mejor adaptación al entorno. En la presente investigación, se analizaron los recursos y capacidades que posee una micro empresa productora de calzado. La metodología tuvo un enfoque cualitativo y un alcance descriptivo, de igual manera, se considera un estudio de caso, ya que se analizó a profundidad y de forma holística a la empresa objeto de estudio. El instrumento usado en este trabajo se compone de
\end{abstract}


"Fl sulber ide mis hijos

Año 13.

Núm. 33

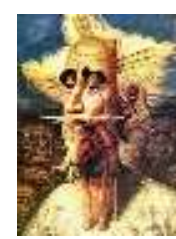

Revista de Investigación

Académica sin Frontera

ISSN: 2007-8870

\title{
http://revistainvestigacionacademicasinfrontera.com
}

Recibido el 5 de agosto de 2020. Dictaminado mediante arbitraje favorablemente 7 de diciembre de 2020.

2 secciones, en la primera se analizan los recursos que posee la organización y en la segunda se examinan las capacidades con las que la empresa cuenta. En los resultados se observa que la empresa posee recursos y capacidades que impulsan su desarrollo, entre los cuales destacan los recursos tangibles y la capacidad de dirección, ventas y distribución y mercadotecnia. Sin embargo, también se identificaron recursos y capacidades que limitan la competitividad de la organización, siendo la marca, la tecnología y la organización, los recursos que necesitan ser reforzados; en cuanto a las capacidades en las cuales se necesitan implementar acciones de mejora están el proceso productivo, desarrollo e investigación y finanzas.

Palabras clave: Empresa productora de calzado, competitividad, recursos y capacidades.

\section{RESOURCES AND CAPABILITIES THAT INFLUENCE THE COMPETITIVENESS OF A FOOTWEAR PRODUCING COMPANY IN THE STATE OF YUCATAN.}

\begin{abstract}
Currently, organizations are under constant pressure to stay in a highly competitive and changing environment, due to this, it is of vital importance for companies to identify the resources and capabilities that drive or limit their competitiveness and based on this, implement strategies competitive that allow a better adaptation to the environment. In the present investigation, the resources and capacities of a footwear micro-company were analyzed. The research methodology had a qualitative approach and a descriptive scope, in the same way, it is considered a case study, since the company under study will be deeply and holistically analyzed. The instrument used in this work is made up of 2 sections, the first one analyzes the resources that the organization possesses and the second examines the capabilities that the company has. The results show that the company has resources and capabilities that drive its development, among which tangible resources and management, sales and distribution and marketing capabilities stand out. However, resources
\end{abstract}


"Fl silwer ile mis hijics

Año 13.

Núm. 33

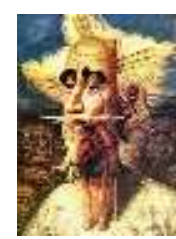

Revista de Investigación

Académica sin Frontera

ISSN: 2007-8870

\section{http://revistainvestigacionacademicasinfrontera.com}

Recibido el 5 de agosto de 2020. Dictaminado mediante arbitraje favorablemente 7 de diciembre de 2020.

and capacities were also identified that limit the competitiveness of the organization, being the brand, the technology and the organization, the resources that need to be reinforced; As for the capacities in which improvement actions need to be implemented are the production process, development and research, and finance.

Keywords: Footwear production company, competitiveness, resources and capabilities.

\section{Introducción}

La globalización, el intercambio de bienes y servicios y la aceleración de los ritmos de apertura económica, han creado un escenario cada vez más competitivo en el cual las organizaciones tienen que gestar su actividad (Castañón, 2005). Esto ha obligado a las empresas a buscar nuevas maneras de elevar su competitividad, debido a que la situación económica se ha vuelto cada vez más complicada (Álvarez, 2016).

La competitividad es sumamente importante para las empresas, especialmente para las micro, pequeñas y medianas (MiPyMes) porque les permite adaptarse a las necesidades cambiantes del mercado y lograr permanencia en este mediante la creación de ventajas competitivas, lo cual genera crecimiento y desarrollo de la industria local. Sallenave (1994) define la competitividad de una empresa como "lo que hace que el consumidor prefiera sus productos y los compre" (p.236). La Teoría de los Recursos y Capacidades se fundamenta en el principio de que la competitividad tiene su origen en los aspectos internos de la empresa, debido a que sobre estos tiene un control directo y le permiten reaccionar ante los factores externos que la puedan afectar.

Suárez e Ibarra (2002) mencionan que:

"El hecho de que los recursos y capacidades se hayan convertido en la base para la estrategia a largo plazo de la empresa descansa en dos premisas: primero, los recursos y capacidades 
"Fl sulber ide mis hijos

Año 13.

Núm. 33

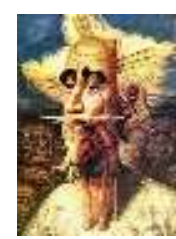

Revista de Investigación

Académica sin Frontera

ISSN: 2007-8870

\section{http://revistainvestigacionacademicasinfrontera.com}

Recibido el 5 de agosto de 2020. Dictaminado mediante arbitraje favorablemente 7 de diciembre de 2020.

internos proveen la dirección básica para la estrategia de la empresa, y segundo, los recursos y capacidades son la principal fuente de rentabilidad para la empresa". (p. 68).

Una de las industrias más relevantes y diversificadas en México es la del calzado, la cual abarca una gran gama de materiales y productos. Son cuatro las entidades de la República Mexicana que concentran el 94\% del valor de la producción de calzado: en Guanajuato se encuentra el 70\% de dichas fábricas, en Jalisco el 15\%, y el 13\% restante corresponde a los Estados de Michoacán, Puebla, Yucatán, Estado de México y Distrito Federal. En todo el territorio nacional existen cerca de 41 mil 500 zapaterías (Secretaría de Economía, 2015).

En el estado de Yucatán se localizan el 5\% de las fábricas de calzado del país, de dicho porcentaje, más de la mitad de las fábricas se encuentran ubicadas en el municipio de Ticul, con una producción aproximada de 453,600 pares de calzado al año (INEGI, 2016). Las empresas ubicadas en el municipio de Ticul, son en su mayoría micro y pequeñas; a nivel nacional las micro y pequeñas empresas representan el 30\% del PIB de México y generan $80 \%$ de empleos en el país (INEGI, 2016). Por lo tanto, las microempresas son un elemento fundamental para el desarrollo económico de México, pues son generadoras de empleo y fomentan el desarrollo y progreso de nuestra nación. (Ulibarri, Madero y Vázquez, 2013).

Como puede observarse, el municipio de Ticul en el estado de Yucatán no figura entre los principales productores a nivel nacional de calzado, esto debido a que la industria del calzado en Ticul enfrenta grandes retos ocasionados por la apertura comercial y el aumento de los competidores. Esta investigación beneficia a las empresas que se dedican a la fabricación de calzado en el municipio de Ticul, Yucatán, debido a que se analizó una unidad de negocio para conocer los recursos y capacidades que están impulsando o limitando su crecimiento, con el fin de plantear acciones de mejora para elevar la competitividad de la organización y que esta pueda 
"Fl silwer ile mis hijics

Año 13.

Núm. 33

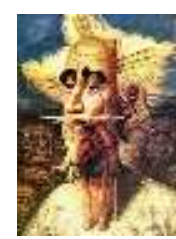

Revista de Investigación

Académica sin Frontera

ISSN: 2007-8870

\section{http://revistainvestigacionacademicasinfrontera.com}

Recibido el 5 de agosto de 2020. Dictaminado mediante arbitraje favorablemente 7 de diciembre de 2020.

adecuarse a las necesidades fluctuantes del mercado, lo cual le permitiría incrementar su posicionamiento y generar un mayor desarrollo en la industria local.

\section{Revisión de la literatura}

En el presente apartado, se realiza una revisión teórica de los principales conceptos relacionados con los recursos y las capacidades, con aportaciones de autores consolidados y trabajos empíricos.

\section{Teoría de los recursos y capacidades.}

En los últimos años de la década de los ochenta, el centro de interés del análisis de la ventaja competitiva se desplazó hacia los aspectos internos de la empresa, apreciándose esta ventaja menos dependiente de las elecciones de la empresa sobre su posición en el mercado y más de la explotación de recursos y capacidades internas únicas (Súarez e Ibarra, 2002).

La teoría de los recursos y capacidades es una opción que permite lograr una ventaja competitiva duradera, que se pueda preservar a lo largo del tiempo, lo cual llevará a la empresa a obtener beneficios económicos reales (Fong, 2005).

De acuerdo con Grant (2010) se deben establecer estrategias basadas en el análisis de las fuerzas particulares de cada empresa con el objetivo de sacar provecho de todos sus recursos y capacidades; de igual manera se necesita determinar los vacíos que puedan generar nuevas oportunidades de negocio. Para lo cual distingue los recursos de las capacidades indicando que los recursos son los factores productivos que posee una empresa y los clasifica como: tangibles, intangibles y humanos. Por otro lado, las capacidades son la esencia de un desempeño superior, ya que son los resultados de un grupo de recursos trabajando juntos. 
"Fl silwer ile mis hijics

Año 13.

Núm. 33
Revista de Investigación

Académica sin Frontera

ISSN: 2007-8870

\section{http://revistainvestigacionacademicasinfrontera.com}

Recibido el 5 de agosto de 2020. Dictaminado mediante arbitraje favorablemente 7 de diciembre de 2020.

\section{Recursos}

Hill y Jones (2011), definen recursos como "los activos de una compañía”. Existen diferencias entre los autores sobre la categorización de los recursos, pero todos coinciden en que, para una empresa, poseer un recurso o varios le ayudará a generar una ventaja competitiva sostenible, obteniendo mayores beneficios en relación con su competencia. Por lo tanto, la organización que los posea y aproveche tendrá mayores posibilidades de permanecer en el mercado, aumentar su rentabilidad y desarrollarse.

Para fines del presente artículo se adoptó la clasificación propuesta por Grant (2010), la cual divide los recursos en tangibles, intangibles y humanos, debido a que es la más actual y se adapta a los objetivos del trabajo.

\section{Recursos tangibles.}

Los recursos tangibles son los más fáciles de identificar, debido a que poseen una parte material, por lo tanto, son cuantificables y medibles por sus características físicas (Nicuesa, 2013). Es decir, son bienes físicos como terreno, edificios, planta, equipo, inventario y capital (Hill y Jones, 2011).

\section{Recursos intangibles.}

Los recursos intangibles son aquellos que no pueden ser medidos ni cuantificados, ya que no cuentan con un soporte físico (Nicuesa, 2013). Se pueden ver reflejados en la reputación de la empresa o el valor de marca y la mayoría de las veces estos son más valiosos que los recursos tangibles debido a que generan presencia y preferencia dentro del mercado, permitiendo a la empresa obtener utilidades superiores a las de sus competidores (Grant, 2010). 
"Fl suber ise mis hiins

Año 13.

Núm. 33
Revista de Investigación

Académica sin Frontera

ISSN: 2007-8870

\section{http://revistainvestigacionacademicasinfrontera.com}

Recibido el 5 de agosto de 2020. Dictaminado mediante arbitraje favorablemente 7 de diciembre de 2020.

\section{Recursos humanos.}

Los recursos humanos hacen referencia al personal que ejerce diversos cargos en la compañía, sus habilidades y competencias (Cardona, 2011). Grant (2010) añade en esta categoría la capacidad de comunicación y colaboración, así como la motivación, la cual hace referencia a la voluntad de llevar a cabo grandes esfuerzos para alcanzar las metas organizacionales y lograr un mejor desempeño.

A continuación, en la tabla 1 se presenta una recopilación de los recursos que cada autor considera importantes dentro de las organizaciones.

\section{Tabla 1}

Los recursos en las organizaciones según diversos autores.

\begin{tabular}{|c|c|c|c|c|c|c|}
\hline & Recursos & $\begin{array}{l}\text { Barney } \\
\text { (1991) }\end{array}$ & $\begin{array}{l}\text { Navas y } \\
\text { Guerra } \\
(2002)\end{array}$ & $\begin{array}{c}\text { Grant } \\
(2010)\end{array}$ & $\begin{array}{l}\text { Hill y } \\
\text { Jones } \\
(2011)\end{array}$ & $\begin{array}{l}\text { Blázquez } \\
\text { y } \\
\text { Mondino } \\
\text { (2012) }\end{array}$ \\
\hline \multirow{9}{*}{ 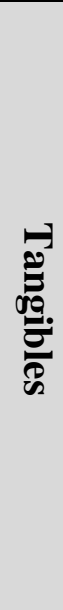 } & Maquinaria y equipo & $X$ & $X$ & $X$ & $X$ & $X$ \\
\hline & $\begin{array}{l}\text { Planta o fábrica } \\
\text { (instalaciones) }\end{array}$ & $X$ & $X$ & $X$ & $X$ & $X$ \\
\hline & Terreno & $X$ & $\mathrm{X}$ & X & $X$ & $X$ \\
\hline & $\begin{array}{l}\text { Materiales e insumos } \\
\text { (materias primas) }\end{array}$ & $X$ & $X$ & $X$ & $X$ & $X$ \\
\hline & Productos terminados & & $X$ & & & \\
\hline & Financieros & & $X$ & X & $X$ & $X$ \\
\hline & Recursos organizativos & & & & & $\mathrm{X}$ \\
\hline & $\begin{array}{l}\text { Humanos desde una } \\
\text { perspectiva tangible }\end{array}$ & & & & & $X$ \\
\hline & Inventarios & & & & $X$ & \\
\hline
\end{tabular}


"Fli suber ide mis hiips

Año 13.

Núm. 33
Revista de Investigación

Académica sin Frontera

ISSN: 2007-8870

\section{http://revistainvestigacionacademicasinfrontera.com}

Recibido el 5 de agosto de 2020. Dictaminado mediante arbitraje favorablemente 7 de diciembre de 2020.

\begin{tabular}{|c|c|c|c|c|c|c|}
\hline \multirow{7}{*}{ 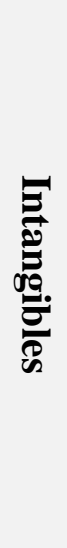 } & $\begin{array}{l}\text { Grado de tecnología } \\
\text { alcanzado }\end{array}$ & $\mathrm{X}$ & $\mathrm{X}$ & & & $\mathrm{X}$ \\
\hline & $\begin{array}{c}\text { Conocimiento, habilidades, } \\
\text { experiencia }\end{array}$ & & $\mathrm{X}$ & & $\mathrm{X}$ & $\mathrm{X}$ \\
\hline & Marca & $\mathrm{X}$ & & $X$ & $X$ & $\mathrm{X}$ \\
\hline & Reputación & & & $\mathrm{X}$ & $\mathrm{X}$ & \\
\hline & Patentes & & & X & $X$ & $\mathrm{X}$ \\
\hline & Propiedad intelectual & & & $\mathrm{X}$ & $X$ & $X$ \\
\hline & $\begin{array}{c}\text { Cultura organizacional } \\
\text { (identidad institucional) }\end{array}$ & & $\mathrm{X}$ & $\mathrm{X}$ & & $\mathrm{X}$ \\
\hline \multirow{4}{*}{ 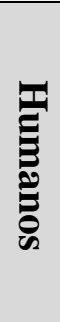 } & $\begin{array}{l}\text { Conocimiento, habilidades, } \\
\text { experiencia (del personal) }\end{array}$ & $\mathrm{X}$ & $X$ & $\mathrm{X}$ & & $\mathrm{X}$ \\
\hline & Capacidad de efectividad & & & & & $\mathrm{X}$ \\
\hline & $\begin{array}{c}\text { Comunicación y trabajo en } \\
\text { equipo }\end{array}$ & & & $\mathrm{X}$ & & $\mathrm{X}$ \\
\hline & Motivación & & & $X$ & & $\mathrm{X}$ \\
\hline
\end{tabular}

Fuente: Elaboración propia.

\section{Capacidades.}

Las capacidades representan las habilidades de la organización para poder obtener ventajas competitivas (Fong, 2005). En el mismo sentido, Hill y Jones (2011) indican que una capacidad es la habilidad con la que cuenta una organización para coordinar sus recursos y colocarlos en usos productivos. Tomando como base las reglas, rutinas y procedimientos de la empresa a través del cual se toman decisiones.

Es importante recalcar que el desarrollo de estas se ve limitado por la ausencia de conocimiento sobre la interacción que debe existir entre los recursos y las capacidades de una organización; el desarrollo de las capacidades se logra normalmente por la integración de recursos de varios tipos y no de uno en particular. Esta interacción se puede lograr mediante el conocimiento 
"Fl sulber ide mis hijise

Año 13.

Núm. 33

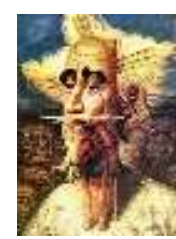

Revista de Investigación

Académica sin Frontera

ISSN: 2007-8870

\section{http://revistainvestigacionacademicasinfrontera.com}

Recibido el 5 de agosto de 2020. Dictaminado mediante arbitraje favorablemente 7 de diciembre de 2020.

y aprendizaje de los procesos existentes en la empresa, así como la difusión y adopción de la cultura organizacional (Grant, 2010).

Este mismo autor, propone elaborar un análisis denominado funcional (ver tabla 2) para obtener las capacidades distintivas de una organización; donde se pretende identificar las capacidades organizativas que están asociadas a cada una de las principales áreas funcionales de la empresa.

\section{Tabla 2.}

\section{Clasificación funcional de las capacidades en las organizaciones.}

\begin{tabular}{|l|l|}
\hline \multicolumn{1}{|c|}{ Área funcional. } & \multicolumn{1}{|c|}{ Capacidades. } \\
\hline Funciones corporativas. & $\begin{array}{l}\text { Control financiero, desarrollo gerencial, innovación estratégica, } \\
\text { coordinación multidivisional, administración de adquisición y } \\
\text { administración de capital. }\end{array}$ \\
\hline Información de gestión & $\begin{array}{l}\text { Seguimiento completo e integrado, red vinculada al equipo gerencial, } \\
\text { toma de decisiones. }\end{array}$ \\
\hline Investigación y desarrollo. & $\begin{array}{l}\text { Investigación, desarrollo e innovación de nuevos productos, desarrollo } \\
\text { de ciclo rápido de nuevos productos. }\end{array}$ \\
\hline Operaciones. & Manufactura eficiente en volumen, mejoras continuas en operaciones. \\
\hline
\end{tabular}

Fuente: Grant (2010, p. 132).

Complementando la tabla anterior, Grant (2010) citado por Carrillo (2019), añade tres capacidades organizativas: 1- La capacidad de diseño de producto, es decir, que la organización desarrolle productos que satisfagan las necesidades de sus clientes y sean innovadores, 2- La mercadotecnia, que incluye la gestión de la marca, la creación de una reputación de calidad de la organización y la capacidad de respuesta a las tendencias del mercado, y por último 3- Las ventas y distribución, que 
"Fli suber ide mis hiips

Año 13.

Núm. 33

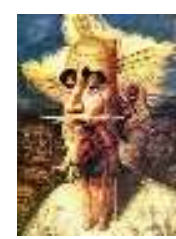

Revista de Investigación

Académica sin Frontera

ISSN: 2007-8870

\section{http://revistainvestigacionacademicasinfrontera.com}

Recibido el 5 de agosto de 2020. Dictaminado mediante arbitraje favorablemente 7 de diciembre de 2020.

engloba la promoción y ejecución efectiva de las ventas, eficiencia y rapidez en el proceso de pedidos, la velocidad de distribución y el servicio brindado al cliente.

\section{Materiales y métodos}

La presente investigación se considera un estudio de caso, ya que se analizó a detalle una empresa productora y comercializadora de calzado, ubicada en el municipio de Ticul, Yucatán. Se llevó a cabo un análisis a profundidad de la organización, visualizándola como un todo, con el objetivo de identificar y explicar los recursos y capacidades que influyen en su competitividad (Bernal, 2000).

Con base en Hernández, Fernández y Baptista (2014), el enfoque de la investigación es de tipo cualitativo, debido a que se busca analizar la forma en que los individuos perciben y experimentan los fenómenos de su entorno, profundizando en sus puntos de vista, interpretaciones y significados. De igual manera, este artículo tiene un alcance descriptivo, debido a que se busca especificar las propiedades y características que distinguen a la empresa estudiada partiendo de su realidad (Hernández et al., 2014). No se realizó manipulación alguna de las variables y se llevó a cabo la observación de la unidad de análisis en su ambiente natural, por lo tanto, cae en la categoría de investigación no experimental (Hernández et al., 2014). Por último, el estudio es de carácter fenomenológico, debido a que su finalidad es explorar, describir y comprender las experiencias de los sujetos de estudio con respecto a un fenómeno y descubrir los elementos en común de tales vivencias (Hernández et al., 2014).

En cuanto a la herramienta empleada para identificar los recursos y capacidades de la organización, se emplea el instrumento diseñado por Carrillo (2019); el cual, se aplica por medio de una entrevista a profundidad, con el objetivo de analizar de manera interna la empresa, cuenta con preguntas para identificar y analizar los recursos y las capacidades de la misma. 
"Fl silwer ile mis hijics

Año 13.

Núm. 33
Revista de Investigación

Académica sin Frontera

ISSN: 2007-8870

\section{http://revistainvestigacionacademicasinfrontera.com}

Recibido el 5 de agosto de 2020. Dictaminado mediante arbitraje favorablemente 7 de diciembre de 2020.

El diseño del instrumento consta de dos secciones y los reactivos son de 46 a 74 en total, dependiendo la jerarquía y el área en la que se ubica cada entrevistado. En la tabla 3 se presentan las variables abordadas en la herramienta.

\section{Tabla 3}

Variables del instrumento de recursos y capacidades.

\begin{tabular}{|c|c|c|c|}
\hline Sección & Categorías & Sub categorías & Reactivos \\
\hline \multirow{9}{*}{ Recursos } & \multirow{3}{*}{ Tangibles } & Maquinaria y equipo & 4 \\
\hline & & Materiales e insumos & 5 \\
\hline & & Planta, instalaciones & 4 \\
\hline & \multirow{3}{*}{ Intangibles } & Marca & 3 \\
\hline & & Reputación & 4 \\
\hline & & Tecnología & 3 \\
\hline & \multirow{3}{*}{ Humanos } & Organización & 4 \\
\hline & & División del trabajo & 4 \\
\hline & & Conocimiento personal & 2 \\
\hline \multirow{6}{*}{ Capacidades } & \multirow{2}{*}{ Dirección general } & Formación académica & 3 \\
\hline & & Liderazgo & 5 \\
\hline & Desarrollo e investigación & & 2 \\
\hline & Mercadotecnia & & 2 \\
\hline & Ventas y distribución & & 5 \\
\hline & Proceso de producción & & 4 \\
\hline
\end{tabular}

Fuente: Carrillo (2019, p. 63). 
"Fl silwer ile mis hijics

Año 13.

Núm. 33
Revista de Investigación

Académica sin Frontera

ISSN: 2007-8870

\section{http://revistainvestigacionacademicasinfrontera.com}

Recibido el 5 de agosto de 2020. Dictaminado mediante arbitraje favorablemente 7 de diciembre de 2020.

\section{Resultados}

Para obtener los resultados sobre los recursos y capacidades que influyen en la competitividad de la empresa productora de calzado, se realizaron cinco entrevistas en total a jefaturas y directivos del organigrama de la empresa. Las personas entrevistadas fueron: el propietario de la organización, el administrador, el encargado de producción, el encargado de almacén y la encargada de ventas.

A continuación, se presentan los resultados obtenidos del instrumento aplicado a los entrevistados, los cuales son propietarios/empleados de la empresa "Calzado Annahi"; con dicho instrumento se determinaron y analizaron los recursos y capacidades con los que cuenta la organización. Es importante mencionar que la información presentada está respaldada por dos o más sujetos de estudio, lo que les da certeza y validez a los resultados. Para mayor facilidad de análisis, en la tabla 4 se menciona el código asignado a cada entrevistado, junto con su nombre y el cargo que ocupa en la organización.

\section{Tabla 4.}

Sujetos de estudio de la empresa "Calzado Annahi”.

\begin{tabular}{|c|c|c|c|}
\hline & Nombre & Cargo & Código \\
\hline 1 & José Luis Chay Abnal & Propietario & $\mathrm{PA}$ \\
\hline 2 & José Luis Chay & Administrador & AA \\
\hline 3 & Sandra Ramírez & Encargada de ventas & EV \\
\hline 4 & Crescencio Cauich Tezec & $\begin{array}{l}\text { Encargado de } \\
\text { producción }\end{array}$ & $\mathrm{EP}$ \\
\hline 5 & José Moo May & Encargado de almacén & EA \\
\hline
\end{tabular}

Fuente: Elaboración propia. 
"Fl sibler ite mis hijise

Año 13.

Núm. 33

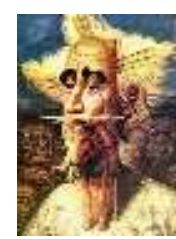

Revista de Investigación

Académica sin Frontera

ISSN: 2007-8870

\section{http://revistainvestigacionacademicasinfrontera.com}

Recibido el 5 de agosto de 2020. Dictaminado mediante arbitraje favorablemente 7 de diciembre de 2020.

\section{Recursos}

Como se indicó en el marco teórico, para fines de la presente investigación, se empleó la clasificación propuesta por Grant (2010), en la cual se dividen los recursos en tangibles, intangibles y humanos.

\section{Recursos tangibles.}

Los recursos tangibles son aquellos bienes que se pueden ver y tocar, estos son importantes para la organización "Calzado Annahi" puesto que en ellos se encuentran incluidos activos como las instalaciones de la empresa y la ubicación de la misma, la maquinaria y equipo para elaborar el calzado, los insumos o materias primas, etc. A continuación, se analiza la información obtenida de los informantes clave.

\section{Maquinaria y equipo.}

Con base en la información recopilada en las entrevistas, de acuerdo con el entrevistado PA, la empresa "cuenta con lo primordial, se sabe que en este medio gran parte de la producción es artesanal, sin embargo, contamos con máquinas de costura, pegado, suaje, equipo para foliar y poner sellos y estas se reparan o renuevan constantemente". Los informantes coinciden en que todas las máquinas son importantes para el proceso de producción porque si faltara una de ellas este se vería seriamente afectado; los informantes EP y EA recalcan que, si bien casi todas las fábricas de calzado debidamente establecidas cuentan con la misma maquinaria y equipo, la embarradora de pegamento y la suajadora, son consideradas a su parecer como un factor de diferenciación entre la empresa y su competencia. Por lo tanto, en lo que respecta a maquinaria y equipo, la empresa se siente a la par frente a empresas similares. 
"Fl silwer ile mis hijics

Año 13.

Núm. 33

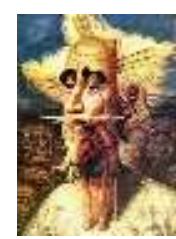

Revista de Investigación

Académica sin Frontera

ISSN: 2007-8870

\section{http://revistainvestigacionacademicasinfrontera.com}

Recibido el 5 de agosto de 2020. Dictaminado mediante arbitraje favorablemente 7 de diciembre de 2020.

\section{Materiales e insumos.}

Continuando con los recursos tangibles, entre los materiales e insumos utilizados para la elaboración del calzado se encuentran: "los forros, los materiales sintéticos, los adhesivos, los químicos, las suelas, tachuelas y hebillas, son los básicos" (PA). En cuanto a la materia prima para elaborar el calzado, un $90 \%$ se obtiene de proveedores locales. La empresa cuenta con un sistema manual de inventario. La compra de materia prima se realiza normalmente de manera semanal (EA); sin embargo, "se han dado meses en los que existe mucha producción y se compra hasta dos veces por semana" (AA). Para conocer cuanta materia prima se requiere adquirir, se realizan juntas semanales entre los encargados de ventas, producción, almacén y el administrador para calcular los insumos necesarios durante la semana (AA y EA). Es importante recalcar que todos los entrevistados coinciden en que la decisión de compra por parte de la empresa se basa principalmente en la calidad de los insumos. Por último, si los insumos adquiridos no cuentan con la calidad requerida por la organización, estos se regresan al proveedor (AA).

\section{Planta e instalaciones.}

Con relación a las instalaciones y la distribución para el área de producción, el taller se divide en cinco partes, 1- El área de corte, 2- El área de ensuelado, 3- El área de acabado 4- El área de costura y 5- El área de almacén (bodega) y entrega de producto terminado (EP). En cuanto a las tiendas, se cuenta con cinco puntos de venta, la matriz, se ubica frente al taller (PA). En cuanto a la remodelación de las instalaciones en el área de taller se han hecho diversas modificaciones, "sobre todo por las normas de salud" (AA). Para finalizar, todos los entrevistados concuerdan en que constantemente se le da mantenimiento al área del taller (reparar maquinaria, ordenar el almacén, reparar las mesas de trabajo) y a los puntos de venta (pintar tiendas, reparar algún desperfecto en techos, etc.). 
"Fl silwer ile mis hijics

Año 13.

Núm. 33

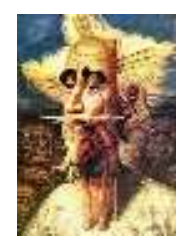

Revista de Investigación

Académica sin Frontera

ISSN: 2007-8870

\section{http://revistainvestigacionacademicasinfrontera.com}

Recibido el 5 de agosto de 2020. Dictaminado mediante arbitraje favorablemente 7 de diciembre de 2020.

\section{Recursos intangibles.}

Los recursos intangibles son los activos que la empresa posee, pero no se pueden ver o tocar. Para fines del presente estudio se recabó información sobre la marca, la reputación y la tecnología con la que cuenta la microempresa analizada.

\section{Marca.}

Los informantes PA y AA indicaron que no se cuenta con un registro de marca ante el Instituto Mexicano de la Propiedad Industrial (IMPI) pero planean a futuro tramitarlo porque lo consideran de vital importancia para continuar expandiendo la organización. Esto supone una desventaja para la empresa debido a que, al no contar con un registro correctamente establecido, existe la posibilidad que otras empresas lo registren o ya se encuentren registradas con el mismo nombre. Con respecto al logotipo de la marca, este está conformado por las palabras "Calzado Annahi" y una mariposa. También, cuentan con el slogan "ideas para tus pies", porque la empresa se encuentra siempre en la constante búsqueda de nuevos modelajes (diseños) de calzado (EV).

\section{Reputación.}

En cuanto a la reputación, de acuerdo con el entrevistado AA, "la empresa cuenta con una buena reputación, tanto con los clientes, como con los proveedores y el gobierno”. Con relación a la promoción de los productos, "la organización asiste a todas las ferias de calzado que se realizan en el municipio, la península de Yucatán y Tabasco, entre las principales destaca la expo calzado Ticul a tu medida y la expo feria del comercio" (EV). También, la empresa participa en La Semana de Yucatán en México, la cual se lleva a cabo en el palacio de los deportes (AA). Para cuidar la calidad del calzado que ofrecen, la empresa cuenta con un sistema de calidad informal (no existe un manual como tal, es por experiencia); los encargados de cada área verifican que el calzado no tenga errores. A pesar de esto, de acuerdo con el informante EP, "siempre existe un margen de 
"Fl silwer ile mis hijics

Año 13.

Núm. 33

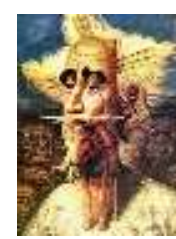

Revista de Investigación

Académica sin Frontera

ISSN: 2007-8870

\section{http://revistainvestigacionacademicasinfrontera.com}

Recibido el 5 de agosto de 2020. Dictaminado mediante arbitraje favorablemente 7 de diciembre de 2020.

error, pero se busca sea mínimo". Por último, "la empresa tiene ventas constantes en los estados de Quintana Roo, Yucatán, Campeche, Tabasco y Chiapas; en ocasiones se envía producto también a los estados de Puebla, Veracruz, México, Hidalgo y Coahuila" (AA). De igual manera, la organización cuenta con presencia en otros países (Guatemala y El Salvador), la cual surge en un principio por medio de un distribuidor (PA).

\section{Tecnología.}

La empresa utiliza internet para publicidad y promoción de sus productos, principalmente Facebook y atención vía WhatsApp (EV). También se cuenta con página web pero en este momento está temporalmente suspendida (AA). En lo referente a la compra de materias primas e insumos, la organización no emplea medios electrónicos (PA). Es importante mencionar que todos los entrevistados coinciden en que la organización es de las primeras que implementaron el uso de Facebook y página web en el municipio, sin embargo, se podrían obtener mayores ventajas si se emplearan medios electrónicos para la adquisición de materias primas.

\section{Recursos humanos.}

De acuerdo con Cardona (2011), los recursos humanos abarcan al personal que labora en la organización, sus habilidades y destrezas. Dichos recursos son de vital importancia para la empresa “Calzado Annahi”.

\section{Organización.}

De acuerdo con los entrevistados PA y AA, la empresa cuenta con un organigrama y un reglamento interno por escrito, sin embargo, los demás informantes comentaron que desconocen la existencia de ambos en forma escrita. En cuanto a capacitación del personal, "constantemente se reciben capacitaciones, pero normalmente son brindadas por los encargados, los cuales tienen muchos años de experiencia en este negocio" (AA). Con respecto a los requisitos solicitados para 
"Fl silwer ile mis hijics

Año 13.

Núm. 33

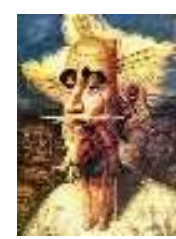

Revista de Investigación

Académica sin Frontera

ISSN: 2007-8870

\section{http://revistainvestigacionacademicasinfrontera.com}

Recibido el 5 de agosto de 2020. Dictaminado mediante arbitraje favorablemente 7 de diciembre de 2020.

ingresar a la organización; los entrevistados EP y EA coinciden en que se les solicitó experiencia en el área de trabajo (el resto de los entrevistados son familia). Es importante mencionar que todos los entrevistados comentaron que se sienten muy a gusto trabajando en la organización.

\section{División del trabajo.}

En lo referente a los departamentos y a las personas encargadas de cada uno, la empresa se encuentra organizada de la siguiente manera: para el área de ventas, la organización cuenta con una encargada principal y adicional a esto, en cada sucursal se cuenta con una encargada de tienda, la cual tiene bajo su cargo a un auxiliar (le apoya en levantar pedidos, guías, encajar producto, maquiladores, etc.) y dos vendedoras. En cuanto al área de taller, todo se reporta con el administrador y existen dos encargados, uno para el área de almacén y el otro para el área de producción, también se cuenta con un bodeguero, el cual reparte las materias primas y productos terminados (AA). Con relación a las prestaciones, todos los entrevistados indicaron que cuentan con las establecidas en la ley. Por último, los informantes coinciden en que el personal de la organización se distingue de su competencia principalmente por el trabajo en equipo, la responsabilidad y el apoyo entre todas las áreas para sacar los pedidos y ventas adelante.

\section{Conocimiento del personal.}

Todos los entrevistados cuentan con conocimiento empírico del área en la cual se desarrollan, solo el administrador cuenta con licenciatura concluida.

\section{Cultura de la organización.}

El informante PA menciona que en la empresa existe una cultura de respeto, un buen clima organizacional, compañerismo y sobre todo apoyo y coordinación entre todas las áreas. Los entrevistados coinciden en que existe una buena integración por parte de los miembros de la 
"Fl suler ide mis hiips harí mi prondezic

Año 13.

Núm. 33

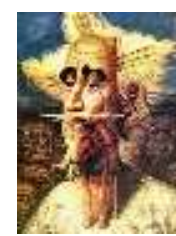

Revista de Investigación

Académica sin Frontera

ISSN: 2007-8870

\section{http://revistainvestigacionacademicasinfrontera.com}

Recibido el 5 de agosto de 2020. Dictaminado mediante arbitraje favorablemente 7 de diciembre de 2020.

empresa y que se fomenta mucho el trabajo en equipo, lo cual permite que la organización se adapte de mejor manera a los cambios del entorno.

En la figura 1 se presenta un resumen de los recursos con los que cuenta la empresa "Calzado Annahi” y se realiza un análisis de cada uno.

Figura 1.

Análisis de los principales recursos de la empresa "Calzado Annahi”.

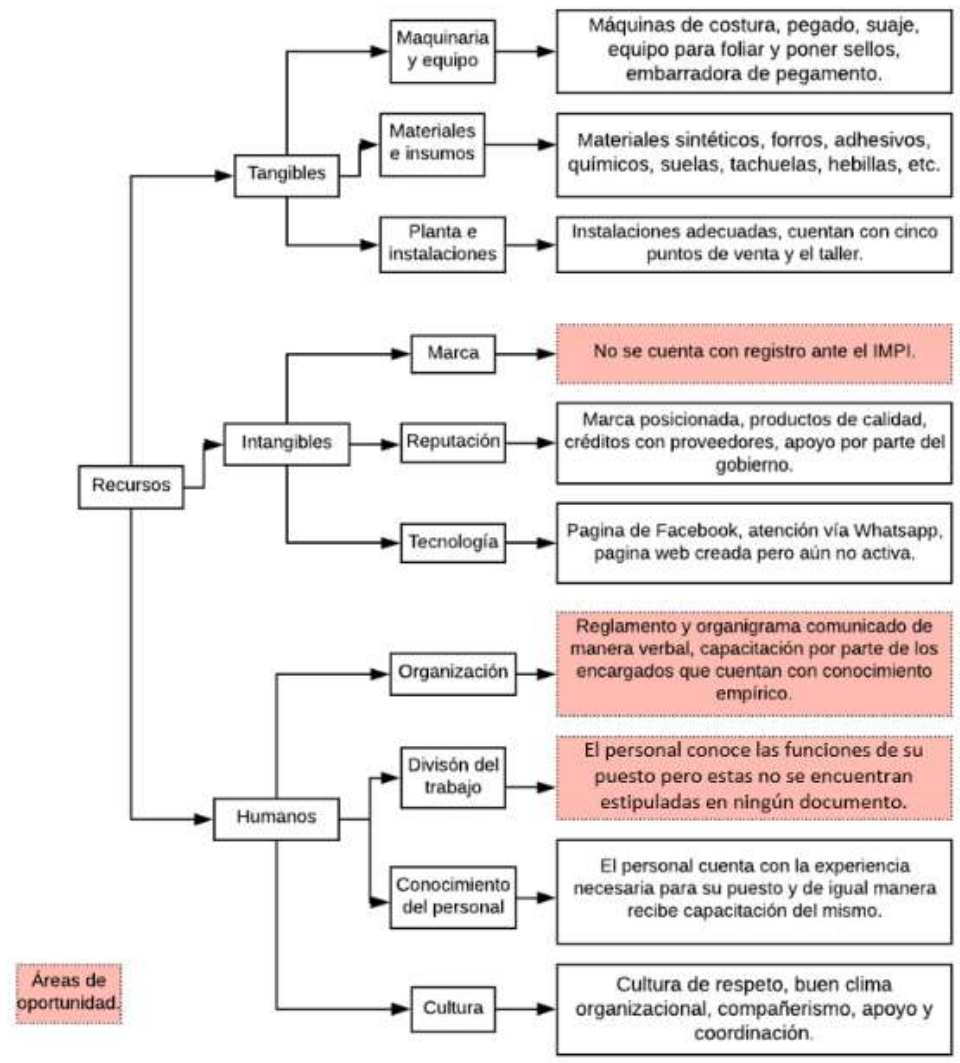

Fuente: Elaboración propia. 
"Fl silwer ile mis hijics

Año 13.

Núm. 33

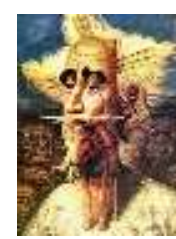

Revista de Investigación

Académica sin Frontera

ISSN: 2007-8870

\section{http://revistainvestigacionacademicasinfrontera.com}

Recibido el 5 de agosto de 2020. Dictaminado mediante arbitraje favorablemente 7 de diciembre de 2020.

Como se puede observar, con respecto a los recursos tangibles, la empresa posee los elementos indispensables para la elaboración del calzado, algunas de sus máquinas no las poseen los talleres pequeños, sin embargo, los más grandes sí. Los materiales e insumos que emplean son de calidad, comparados con los empleados por algunos de sus competidores de acuerdo con lo indicado por los entrevistados. Las instalaciones de la empresa son adecuadas (se encuentran recientemente remodeladas, tanto el área de producción como los puntos de venta). En cuanto a los recursos intangibles, la organización cuenta con una buena reputación con los clientes, proveedores y gobierno; emplea la tecnología para dar a conocer sus productos, por medio de redes sociales y próximamente por página web. Sin embargo, no cuenta con un registro de logotipo y marca, lo cual la deja en desventaja contra sus competidores que sí lo poseen y podría ser un problema mayor a futuro si el nombre ya se encuentra registrado por otra empresa. Por último, en relación con los recursos humanos, a pesar de que todo el personal conoce las jerarquías, normas y funciones a realizar en la organización, esta no cuenta con un organigrama debidamente establecido y tampoco existe un reglamento por escrito, no obstante, existe un buen clima laboral y una cultura organizacional de respeto, responsabilidad y trabajo en equipo.

\section{Capacidades.}

Las capacidades son las habilidades que posee una empresa que le permiten administrar de manera adecuada y productiva sus recursos; utilizando siempre como punto de partida las reglas, rutinas y procesos con los que cuenta la organización para tomar decisiones (Hill y Jones, 2011). Para fines del presente estudio, se analizaron las siguientes capacidades organizacionales: dirección general, proceso productivo, desarrollo e investigación, mercadotecnia, ventas y finanzas. 
"Fl silwer ile mis hijics

Año 13.

Núm. 33

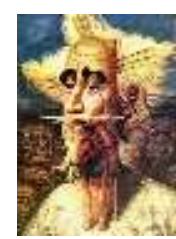

Revista de Investigación

Académica sin Frontera

ISSN: 2007-8870

\section{http://revistainvestigacionacademicasinfrontera.com}

Recibido el 5 de agosto de 2020. Dictaminado mediante arbitraje favorablemente 7 de diciembre de 2020.

\section{Dirección general.}

En la empresa "Calzado Annahi” las decisiones principalmente eran tomadas por el entrevistado PA, sin embargo, la empresa se encuentra en un proceso de sucesión en el cual el propietario está delegando la toma de decisiones a su hijo, el informante AA, por lo cual se tomaron en cuenta las respuestas de ambos. En cuanto al informante PA, su último nivel de estudios es la preparatoria trunca, no obstante, toda su vida ha estado en contacto con el proceso de fabricación de calzado. Con respecto a la decisión para fundar la empresa, esta se debió al deseo de independizarse del negocio familiar. En lo referente al entrevistado AA, su formación académica es la Licenciatura en Gestión Empresarial, lo cual le ha permitido desarrollar de manera adecuada el puesto de administrador. La decisión de tomar dicho puesto se debe, en palabras del informante "a mi padre, el cual me pidió le apoye en la empresa familiar" (AA). El informante AA indica que un factor clave para un buen liderazgo en la empresa es la paciencia y mantener a los trabajadores motivados. Por último, ambos entrevistados coinciden en que un aspecto que se debe mejorar es la rotación de personal en el área de ventas, debido a que se invierte tiempo y recursos en capacitarlas para que al poco tiempo solo dejen de ir sin avisar.

\section{Proceso productivo.}

Con respecto al proceso de producción, la empresa no cuenta con un manual por escrito. De igual manera, los entrevistados AA y EP, coinciden en que la organización no tiene ningún procedimiento o materia prima diferente a su competencia. En lo referente a la estandarización de procesos, la organización cuenta con un patrón por diseño de calzado y por tallas, sin embargo, en cuanto a los tiempos de producción, no se cuenta con un estándar (AA). Para finalizar, los entrevistados coinciden en que la organización se adapta de manera adecuada a los cambios del entorno. 
"Fl suber ise mis hijos

Año 13.

Núm. 33
Revista de Investigación

Académica sin Frontera

ISSN: 2007-8870

\section{http://revistainvestigacionacademicasinfrontera.com}

Recibido el 5 de agosto de 2020. Dictaminado mediante arbitraje favorablemente 7 de diciembre de 2020.

\section{Desarrollo e investigación.}

Los informantes PA y AA coinciden en que es un área que necesitan fortalecer, sin embargo, "constantemente se realizan viajes a ferias de calzado en otros estados, se consultan catálogos de las grandes empresas productoras de calzado como Andrea e Impuls y se emplea el internet para mantener a la empresa en tendencia en cuanto a modelaje" (AA).

\section{Mercadotecnia.}

En relación con la mercadotecnia, la empresa recientemente "actualizó su logotipo para hacerlo más moderno y tener los editables" (EV). De igual manera, la organización emplea redes sociales (Facebook y Whatsapp) para compartir promociones, dar a conocer el catálogo de productos, suscribirse en las futuras expos en las cuales participarán y brindar asesoría a los clientes (AA).

\section{Ventas y distribución.}

Con respecto al número de empresas que pueden adquirir los productos, la organización cuenta con una cartera de clientes fijos, el informante AA menciona que "los compradores se encuentran satisfechos por la atención que se les da por parte de la empresa". Para la logística de distribución del calzado, la empresa pacta una fecha de entrega o envío del producto y se agenda en la ruta del día programado. Por último, la empresa solo maneja promociones por mayoreo y las encargadas de tienda son responsables de llevar un registro de las ventas por sucursal. 
"Fl silwer ile mis hijics

Año 13.

Núm. 33

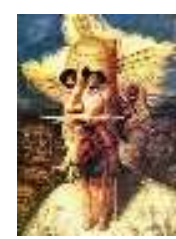

Revista de Investigación

Académica sin Frontera

ISSN: 2007-8870

\section{http://revistainvestigacionacademicasinfrontera.com}

Recibido el 5 de agosto de 2020. Dictaminado mediante arbitraje favorablemente 7 de diciembre de 2020.

\section{Finanzas.}

Los propietarios en conjunto con el contador se encargan de llevar un registro de los costos e ingresos (PA y AA). Sin embargo, el informante AA indica que es complicado algunas veces debido a la cantidad de producción y a que el contador es externo a la empresa.

A continuación, se presenta en la figura 2, un resumen de las capacidades con las que cuenta la organización y se menciona cuales necesitan ser fortalecidas.

\section{Figura 2}

Análisis de las capacidades de la empresa "Calzado Annahi”.

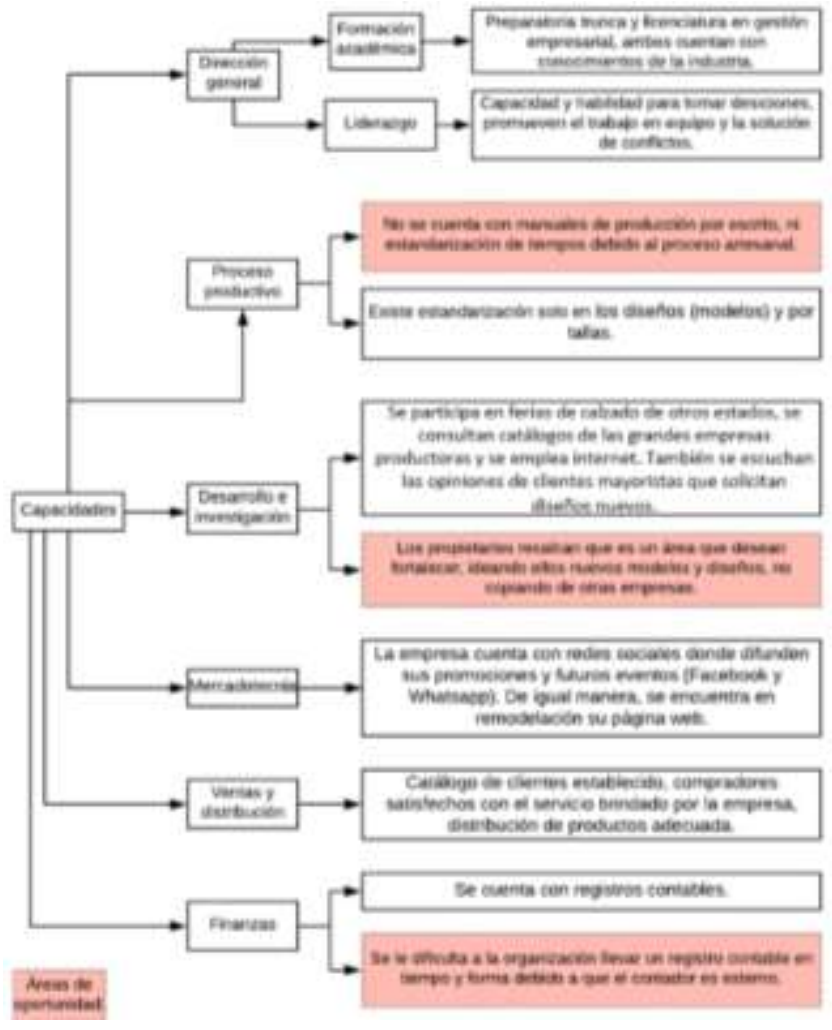

Fuente: Elaboración propia. 
"Fl suber ite mis hijics

Año 13.

Núm. 33
Revista de Investigación

Académica sin Frontera

ISSN: 2007-8870

\section{http://revistainvestigacionacademicasinfrontera.com}

Recibido el 5 de agosto de 2020. Dictaminado mediante arbitraje favorablemente 7 de diciembre de 2020.

Como se puede observar, existen tres capacidades que es necesario fortalecer: 1- Proceso productivo, debido a que la organización no cuenta con diagramas o manuales de producción por escrito, solo existen de manera verbal. 2- Desarrollo e investigación, a pesar de que la empresa se encuentra en constante búsqueda de las últimas tendencias en cuanto a diseños, el propietario indica que es una capacidad que se necesita fortalecer para poder incursionar en nuevos mercados con diseños propios y no tomados de otras organizaciones. 3- Finanzas, debido a que, aunque se cuenta con un registro contable de manera manual, en ocasiones se generan complicaciones debido a que el contador es externo a la compañía y se depende de sus tiempos.

\section{Conclusiones}

A continuación, se presentan los recursos y las capacidades que impulsan la competitividad de la empresa Calzado Annahi.

Los recursos que se encuentran presentes en la organización e impulsan su competitividad son los siguientes (ver tabla 5):

\section{Tabla 5.}

Recursos que impulsan la competitividad de la empresa objeto de estudio.

\begin{tabular}{|c|c|c|}
\hline Sección & Categoría & Sub categoría \\
\hline \multirow{4}{*}{ Recursos } & \multirow{3}{*}{ Tangibles } & Maquinaria y equipo \\
\cline { 3 - 3 } & & Materiales e insumos \\
\cline { 2 - 3 } & Intangibles & Planta, instalaciones \\
\cline { 2 - 3 } & \multirow{3}{*}{ Humanos } & $\begin{array}{c}\text { Cultura de la } \\
\text { organización }\end{array}$ \\
\cline { 2 - 3 } & & Conocimiento personal \\
\hline
\end{tabular}

Fuente: Elaboración propia. 
"Fl suber ite mis hijics

Año 13.

Núm. 33

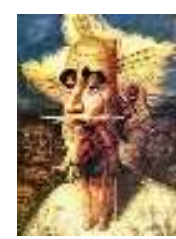

Revista de Investigación

Académica sin Frontera

ISSN: 2007-8870

\section{http://revistainvestigacionacademicasinfrontera.com}

Recibido el 5 de agosto de 2020. Dictaminado mediante arbitraje favorablemente 7 de diciembre de 2020.

Como se puede observar en la tabla 5, los recursos tangibles son de vital importancia para impulsar la competitividad de la empresa. Con respecto a maquinaria y equipo, la organización cuenta con lo primordial para el giro en el cual se desenvuelve, sin embargo, son conscientes que este tipo de recursos suelen imitarse con facilidad, por lo cual buscan mantenerse actualizados y adquirir nuevos equipos si el negocio lo requiere. En cuanto a materiales e insumos, la organización cuenta con todo lo necesario para la elaboración del calzado y adquiere dichos productos con base en su calidad, debido a que busca que esta sea el factor diferenciador con respecto a su competencia. En relación con las instalaciones, el taller y los puntos de venta se encuentran bien ubicados, debidamente divididas las áreas y en remodelación constante, con el objetivo de facilitar el trabajo. Respecto a la reputación, la empresa tiene una buena reputación, tanto con sus clientes, gracias a la calidad en sus productos y la atención que les brinda a estos; como con los proveedores, gracias a que siempre se cumplen los tiempos de pago pactados y con el gobierno del municipio, debido a que constantemente participan en los programas que este imparte. Este es un recurso de vital importancia para la organización, dado que le ha permitido crear lealtad a la marca por parte de determinados clientes, tener acceso a mayores créditos con proveedores y apoyos en los programas impulsados por el Ayuntamiento de Ticul. Por último, en cuanto a la cultura de la organización y el conocimiento del personal, son recursos valiosos que diferencian a la empresa de su competencia, puesto que, los empleados cuentan con años de experiencia en su puesto de trabajo, desempeñando adecuadamente su labor y los trabajadores coinciden en que la cultura de la organización es de respeto y trabajo en equipo, lo que ayuda a que el personal sea más productivo y por ende influya en la competitividad de la empresa.

De igual manera, las capacidades que se encuentran consolidadas e impulsan a la organización y le ayudan a ser más competitiva, fueron las siguientes: 
"Fl silwer ile mis hijics

Año 13.

Núm. 33
Revista de Investigación

Académica sin Frontera

ISSN: 2007-8870

\section{http://revistainvestigacionacademicasinfrontera.com}

Recibido el 5 de agosto de 2020. Dictaminado mediante arbitraje favorablemente 7 de diciembre de 2020.

Dirección general: aunque solo el hijo del dueño, el administrador, cuenta con licenciatura afín al giro de la organización, ambos cuentan con conocimientos de la industria, debido a que han estado involucrados en ese giro desde pequeños. De igual manera, ambos tienen capacidad para liderar al personal a su cargo, promueven el trabajo en equipo y la solución de conflictos, lo cual propicia un buen clima laboral en la organización.

Ventas y distribución: la empresa cuenta con una cartera de clientes sólida, un servicio al cliente de calidad, entrega de productos en tiempo y forma y efectividad de la promoción de ventas.

Mercadotecnia: la empresa cuenta con redes sociales en las cuales dan a conocer sus productos, promociones y fechas de futuros eventos, de igual manera, se encuentra en remodelación su página web, por medio de la cual se pretende tener un mayor alcance.

Por el contrario, los recursos y las capacidades que limitan la competitividad de la organización analizada se dividen de la siguiente manera:

En cuanto a los recursos que es necesario reforzar, debido a que podrían ser una limitante a futuro para la empresa, se encuentran los siguientes (ver tabla 6):

\section{Tabla 6.}

\section{Recursos a reforzar en la empresa objeto de estudio.}

\begin{tabular}{|c|c|c|}
\hline \multirow{2}{*}{ Sección } & Categoría & Sub categoría \\
\hline \multirow{2}{*}{ Recursos } & \multirow{2}{*}{ Intangibles } & Marca \\
\cline { 2 - 3 } & & Tecnología \\
\cline { 2 - 3 } & \multirow{2}{*}{ Humanos } & Organización \\
\cline { 2 - 3 } & & División del trabajo \\
\hline
\end{tabular}

Fuente: Elaboración propia. 
"Fl silwer ile mis hijics

Año 13.

Núm. 33

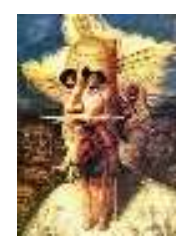

Revista de Investigación

Académica sin Frontera

ISSN: 2007-8870

\section{http://revistainvestigacionacademicasinfrontera.com}

Recibido el 5 de agosto de 2020. Dictaminado mediante arbitraje favorablemente 7 de diciembre de 2020.

Como se puede observar en la tabla 6 , en cuanto a los recursos intangibles que es necesario fortalecer, se identificó que la organización no cuenta con un registro de marca debidamente establecido ante el IMPI, por lo que otra compañía podría ya haber registrado el nombre empleado por la empresa objeto de estudio. De igual manera, en cuanto a la tecnología se encontró que, si bien la empresa emplea redes sociales para dar a conocer sus productos, se sugiere fortalecer este aspecto en el proceso productivo y compra de materia prima. En cuanto a organización, es necesario reforzar dicho factor para que no se convierta en una limitante a futuro, debido a que, de acuerdo con los directivos, la empresa cuenta con un organigrama y un reglamento por escrito, sin embargo, el resto del personal indicó que solo lo conocen de manera verbal. Siendo el mismo caso para la división del trabajo y las funciones a realizar en cada puesto, las cuales se conocen por todo el personal, pero no se encuentran escritas en un documento oficial.

Por último, se enlistan las capacidades que es necesario fortalecer por parte de la organización debido a que en un futuro pueden volverse una limitante para la competitividad de la empresa:

El proceso productivo, debido a que la empresa no cuenta con manuales de producción/procesos por escrito.

Desarrollo e investigación, a pesar de que la organización está pendiente de las últimas tendencias en cuanto a diseño y se realizan visitas de exploración a ferias y exposiciones de calzado, los propietarios consideran que es una capacidad que se necesita fortalecer, dado que la organización desea en un futuro elaborar sus propios diseños y que estos se vuelvan tendencia.

Finanzas, la empresa procura registrar todos sus ingresos y egresos y llevar un registro adecuado para tomar en cuenta todos sus costos y ganancias, sin embargo, esto resulta complicado debido a 
"Fl silwer ile mis hijics

Año 13.

Núm. 33

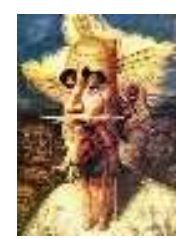

Revista de Investigación

Académica sin Frontera

ISSN: 2007-8870

\section{http://revistainvestigacionacademicasinfrontera.com}

Recibido el 5 de agosto de 2020. Dictaminado mediante arbitraje favorablemente 7 de diciembre de 2020.

que el contador es externo a la empresa y en ocasiones existen problemas de comunicación que dificultan tener la información actualizada.

\section{Recomendaciones}

En cuanto a los recursos tangibles, se sugiere que la empresa siga adquiriendo maquinaria y equipo que eficiente sus procesos, al igual que materiales e insumos de calidad y que continúe renovando sus instalaciones. De igual manera, se propone en caso de que la compañía busque crecer hacia otros mercados, una renovación de la maquinaria que se encuentre obsoleta. También se propone instalar equipos de seguridad en el taller, para tener un mejor control de la materia prima y evitar mermas o robos.

En los recursos intangibles, se propone que la organización verifique si el nombre de la marca no se encuentra registrado ante el Instituto Mexicano de la Propiedad Industrial (IMPI) y de estar disponible, que se inicie el trámite para obtener la propiedad del nombre. Esto con el objetivo de evitar problemas de plagio en el futuro. De igual manera, se sugiere para el rubro de tecnología la adquisición de equipo de cómputo para llevar un mejor control de inventarios, materias primas y producto terminado en el área de taller y posteriormente considerar la adquisición de algún software para un mejor control de inventarios.

Con respecto a los recursos humanos se sugiere que la empresa establezca por escrito y de manera oficial el organigrama, reglamento, los perfiles de puestos y las actividades a realizar en cada puesto por área, esto con el objetivo de conocer las líneas formales de comunicación, las normas a seguir en la organización, los conocimientos con los que debe contar el responsable de cada área y el personal a su cargo y detectar que no se estén omitiendo actividades o duplicando procesos. De igual manera, se propone a la empresa que se continúe con la capacitación de manera 
"Fl silwer ile mis hijics

Año 13.

Núm. 33

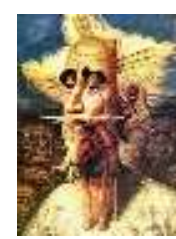

Revista de Investigación

Académica sin Frontera

ISSN: 2007-8870

\section{http://revistainvestigacionacademicasinfrontera.com}

Recibido el 5 de agosto de 2020. Dictaminado mediante arbitraje favorablemente 7 de diciembre de 2020.

empírica, pero se considere también participar en los cursos y talleres impartidos por las diversas cámaras que conforman la industria del calzado y el gobierno.

Con referencia a las capacidades, se recomienda continuar preparándose y reforzando su formación académica a los directivos y al personal que labora en la empresa. En cuanto al proceso de producción se sugiere que se establezcan manuales que documenten por escrito todas las actividades realizadas durante el mismo para que se puedan ir actualizando conforme se requiera y detectar y corregir errores de ser necesario. Con respecto al desarrollo e investigación, se propone a la empresa continuar explorando el mercado para mantenerse al tanto de los cambios en el sector y de ser necesario, hacer sinergia con algún diseñador si se quiere crear modelos diferentes a los existentes en el mercado actual. En lo referente a la mercadotecnia, se sugiere reforzar la imagen corporativa (haciendo visible para los empleados la misión, visión y valores de la empresa, proporcionando a los trabajadores uniformes con el logo de la compañía, rotular los vehículos de reparto) para reforzar la comunicación y la cultura de la empresa. También se propone la adquisición de un software de diseño como Adobe Illustrator o Adobe Photoshop para que en un futuro la empresa pueda desarrollar su publicidad. Por último, en cuanto a finanzas, se recomienda contratar a una persona dedicada exclusivamente a llevar la contabilidad de la organización, debido a que esto facilitaría la comunicación y estaría más familiarizada con la operación diaria de la empresa.

\section{Referencias.}

Álvarez, C. (2016). Un modelo de productividad y competitividad para la gestión de operaciones. Mercados y Negocios. (1665-7039), (14), 61-78.

Barney, J. (1991). Firm Resources and Sustained Competitive Advantage. Journal of Management. 17(1), pp. 99-120. 
"Fl silwer ile mis hijics

Año 13.

Núm. 33

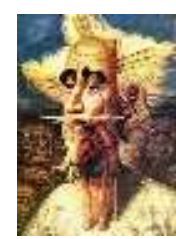

Revista de Investigación Académica sin Frontera

ISSN: 2007-8870

\section{http://revistainvestigacionacademicasinfrontera.com}

Recibido el 5 de agosto de 2020. Dictaminado mediante arbitraje favorablemente 7 de diciembre de 2020.

Bernal, C. A. (2000). Metodología de la investigación para administración y economía. Bogotá: Prentice Hall Pearson.

Blázquez, M., y Mondino, A. (2012). Recursos organizacionales: Concepto, clasificación e indicadores. Técnica administrativa, vol. 11, No. 49.

Cardona, A. (2011). Estrategia basada en los recursos y capacidades. Criterios de evaluación y el proceso de desarrollo. Revista Electrónica Forum Doctoral, 113-147.

Carrillo, A. (2019). Influencia de los recursos, las capacidades y el entorno sectorial en la competitividad de una empresa fabricante de calzado en Ticul, Yucatán. (tesis de maestría). Instituto Tecnológico de Mérida. Yucatán, México.

Castañón, R. (2005). La política industrial como eje conductor de la competitividad en las Pyme. México: Fondo de cultura económica.

Fong, C. (2005). Teoría de los recursos y capacidades. Fundamentos microeconómicos. Universidad de Guadalajara. México.

Grant, R. (2010). Contemporary Strategy Analysis. United Kingdom: John Wiley y Sons Ltd, (7 ed.).

Hernández, R., Fernández, C., y Baptista, P. (2014). Metodología de la investigación. México: MC Graw Hill.

Hill, C., y Jones, G. (2011). Administración Estratégica. México. Mc Graw Hill.

Instituto Nacional de Estadísticas y Geografía. (2016). Directorio Estadístico nacional de Unidades Económicas. Recuperado el 21 de febrero de 2019, de INEGI: http://www.beta.inegi.org.mx/app/mapa/denue/default.aspx 
"Fl silwer ile mis hijics

Año 13.

Núm. 33
Revista de Investigación

Académica sin Frontera

ISSN: 2007-8870

\section{http://revistainvestigacionacademicasinfrontera.com}

Recibido el 5 de agosto de 2020. Dictaminado mediante arbitraje favorablemente 7 de diciembre de 2020.

Navas, L., y Guerras M. (2002). La dirección estratégica de la empresa. Teoría y aplicaciones, 3.a edición, Madrid. 186, 187.

Nicuesa, M. (2013). Recursos tangibles e intangibles en la empresa. Empresariados. Recuperado el 11 de enero de 2019 de, http://empresariados.com/recursos tangibles-e-intangibles-en-laempres/

Sallenave, J. (1994). La gerencia integral. Bogotá, Colombia. Norma S.A.

Secretaría de Economía. (2015). gob.mx. Recuperado el 01 de noviembre de 2018, de https://www.gob.mx/se/articulos/la-industria-del-calzado-en-mexico.

Suárez, J., e Ibarra, S. (2002). La teoría de los recursos y las capacidades. Un enfoque actual en la estrategia empresarial. Dialnet, 63-89.

Ulibarri, A., Madero, E., y Vázquez, E. (2013). La calidad en el servicio en las tiendas de abarrotes y un minisúper del fraccionamiento Francisco de Montejo en la ciudad de Mérida Yucatán. Congreso virtual internacional sobre contaduría y administración, 1-17. 
"Fl suler ide mis hiipss

Año 13.

Núm. 33
Revista de Investigación

Académica sin Frontera

ISSN: 2007-8870

http://revistainvestigacionacademicasinfrontera.com

Recibido el 5 de agosto de 2020. Dictaminado mediante arbitraje favorablemente 7 de diciembre de 2020.

\section{Directorio Institucional}

Dr. Enrique Fernando Velázquez Contreras

Rector

Dr. Ramón Enrique Robles Zepeda

Secretario General Académico

Dra. Rosa María Montesinos Cisneros

Secretaria General Administrativa

Dr. Rodolfo Basurto Álvarez

Director de Vinculación y Difusión

Dra. Adriana Leticia Navarro Verdugo

Vicerrectora de la Unidad Regional Sur

Dr. Ernesto Clark Valenzuela

Director de la División de Ciencias Económicas y Sociales

Dr. Francisco Espinoza Morales

Secretario de la División de Ciencias Económico y Sociales

Dra. Leticia María González Velásquez

Jefe del Departamento de Ciencias Económico Administrativas

Dra. Lidia Amalia Zallas Esquer

Jefe de Departamento de Ciencias Sociales 
"Fl suler ide mis hiipses

Año 13.

Núm. 33

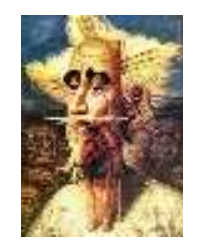

Revista de Investigación

Académica sin Frontera

ISSN: 2007-8870

\section{http://revistainvestigacionacademicasinfrontera.com}

Recibido el 5 de agosto de 2020. Dictaminado mediante arbitraje favorablemente 7 de diciembre de 2020.

\section{Comité Directivo}

\section{Editor Responsable}

Dr. Francisco Espinoza Morales

\section{Directora}

Dra. Leticia María González Velásquez

\section{Subdirector}

Dr. Javier Carreón Guillen

\section{Editor Científico}

Dr. Cruz García Lirios

\section{Master Gráfico}

M.T.I. Francisco Alan Espinoza Zallas

Nos complace anunciar que su diario, "Academic Research Journal Withoutborders" (ISSN/EISSN 20078870) fue evaluado positivamente en la indexación Citefactor, ahora la página de la revista está disponible en línea, en caso de cualquier problema.

Journals Master | International Innovative Journal Impact Factor (IIJIF)

\section{Red Latinoamericana de revistas Académicas en Ciencias Sociales y Humanidades}

\section{CiteFactor}

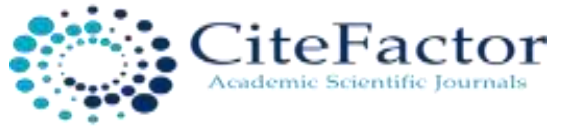

Dra. Angélica María Rascón Larios Universidad de Sonora. México
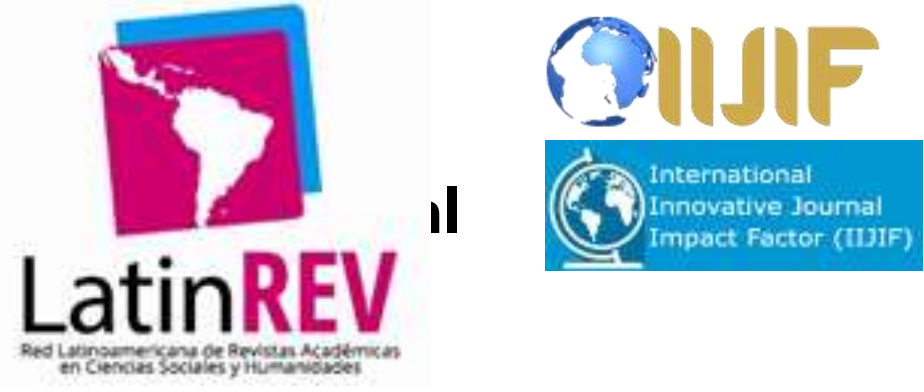
"Fl silwer ise mis hijics

Año 13.

Núm. 33
Revista de Investigación

Académica sin Frontera

ISSN: 2007-8870

http://revistainvestigacionacademicasinfrontera.com

Recibido el 5 de agosto de 2020. Dictaminado mediante arbitraje favorablemente 7 de diciembre de 2020.

\section{Comité Editorial}

Dra. María del Rosario Molina González

Universidad de Sonora

Dra. Francisca Elena Rochin Wong

Universidad de Sonora. México

Dra. Lidia Amalia Zallas Esquer

Universidad de Sonora. México

Dra. Beatriz Llamas Arechiga

Universidad de Sonora. México

Dr. Rogelio Barba Álvarez

Universidad de Guadalajara. México

Dra. Rosa María Rincón Ornelas

Universidad de Sonora. México

Dr. Juan Flores Preciado

Universidad de Colima. México

Dr. Amado Olivares Leal. Universidad de Sonora

Universidad de Sonora. México

Dr. Guillermo Velázquez Valadez.

Instituto Politécnico Nacional (IPN) México

Dr. Hugo Nefstalí Padilla Torres.

Universidad Estatal de Sonora. México

Dr. Luis Ramón Moreno Moreno.

Universidad Autónoma de Baja California. México

Dr. Miguel Ángel Vázquez Ruiz.

Universidad de Sonora. México

Dra. Lorena Vélez García.

Universidad Autónoma de Baja California. México 
"Fl siler ite mis hijisa

Año 13.

Núm. 33
Revista de Investigación

Académica sin Frontera

ISSN: 2007-8870

http://revistainvestigacionacademicasinfrontera.com

Recibido el 5 de agosto de 2020. Dictaminado mediante arbitraje favorablemente 7 de diciembre de 2020.

Dra. Pabla Peralta Miranda.

Universidad Simón Bolívar, Barranquilla, Colombia

Mtro. Roberto Espíritu Olmos

Universidad de Colima (FCA Tecomán) Colima

Dr. Héctor Priego Huertas.

Universidad de Colima (FCA Tecomán) Colima

Mtra. María Guadalupe Alvarado Ibarra.

Universidad de Sonora. México.

MSc. Celso Germán Sánchez Zayas

Universidad de Camagüey, Ignacio Agramonte Loynaz, Cuba

Dra. María Luisa Quintero Soto

Universidad Autónoma del Estado de México

Dr. Eyder Bolivar Mojica

Universidad Católica, Luis Amigó, Medellin, Colombia

Revisores de Textos en Inglés

Mtro. Renato Encinas

Mtra. Cecilia Guadalupe Martínez Solano 


\section{http://revistainvestigacionacademicasinfrontera.com}

Recibido el 5 de agosto de 2020. Dictaminado mediante arbitraje favorablemente 7 de diciembre de 2020.

\section{Comité científico}

Dr. Rosendo Martínez Jiménez. Universidad Autónoma Benito Juárez de Oaxaca.

Dr. Hugo Neftalí Padilla. Universidad Estatal de Sonora

Dra. María Teresa Gaxiola Sánchez. Universidad de Sonora.

Dr. José Cesar Kaplan. Universidad Estatal de Sonora.

Dr. Alfredo Islas Rodríguez. Universidad de Sonora

Frecuencia de publicación: semestral / 2 números por año.

Revista de Investigación Académica sin Frontera (RIASF) con (ISSN: 2007-8870) es un interlocutor internacional de acceso abierto revisado diario en línea en el ámbito del de las Ciencias Económicas Administrativas y Sociales. Su objetivo principal es dar a los trabajos de investigación de calidad. Cubre todas las sub-campos de los campos anteriormente mencionados. Proporciona la plataforma a académicos, estudiantes y profesionales. Sólo pública trabajos de investigación y artículos de revisión inicial. Documento presentado debe cumplir con algunos criterios como, debe ser original, inédita y no estén sometidos a ninguna otra revista.

RIASF es una revista arbitrada / Revisión por pares International. Publicamos documentos sobre una variedad de temas, contextos y estrategias de análisis que examinan la relación entre la rápida evolución para la Sociedad y la tecnología del conocimiento.

REVISTA DE INVESTIGACIÓN ACADÉMICA SIN FRONTERA, Año 13, No. 33, Julio - diciembre 2020, es una publicación semestral de investigación científica, editada por la Universidad de Sonora, a través de las División de Ciencias Económicas y Sociales, de la Unidad Regional Sur, Blvd. Lázaro Cárdenas No. 100, Col. Francisco Villa, Navojoa, Sonora, Sonora, México, C.P. 85880. Tel. (642) 425- 99-54.

http://www.revistainvestigacionacademicasinfrontera.com/, revistaacademicasinfrontera@unison.mx.

Editor responsable: Francisco Espinoza Morales. Reserva de Derechos al Uso Exclusivo: 04-2013121811323700-203 e ISSN: 2007-8870, ambos otorgados por el Instituto Nacional de Derecho de Autor. Inscrita en el Directorio de LATINDEX, con Núm. De folio 20014, folio único 14590. Responsable de la última actualización de este Número, Unidad Informática de la Universidad de Sonora, fecha de la última modificación, 30 de diciembre 2020, indexada a Cite Factor Academic Scientific Journal y Journals Master (IIJIF) y Red Latinoamericana de Revistas Académicas en Ciencias Sociales y Humanidades, (Latín Rev). Las opiniones expresadas por los autores no necesariamente reflejan la postura del editor de la publicación. Se autoriza la reproducción total o parcial de los contenidos e imágenes en la presente publicación siempre y cuando se cuente con la autorización del editor y se cite plenamente la fuente. 
"Fl suler ide mis hiipss

Año 13.

Núm. 33

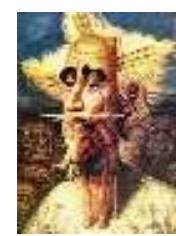

Revista de Investigación Académica sin Frontera

ISSN: 2007-8870

\section{http://revistainvestigacionacademicasinfrontera.com}

Recibido el 5 de agosto de 2020. Dictaminado mediante arbitraje favorablemente 7 de diciembre de 2020.

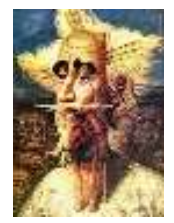

Nos complace anunciar que su diario, "Academic Research Journal Withoutborders" (ISSN/EISSN 20078870) fue evaluado positivamente en la indexación Citefactor, ahora la página de la revista está disponible en línea, en caso de cualquier problema.

Journals Master | International Innovative Journal Impact Factor (IIJIF)

\section{Red Latinoamericana de revistas Académicas en Ciencias Sociales y Humanidades}

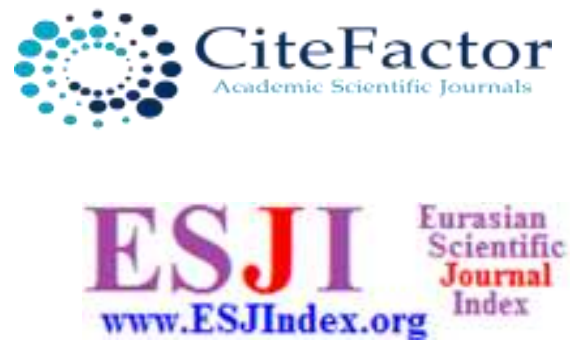

https://www.neliti.com

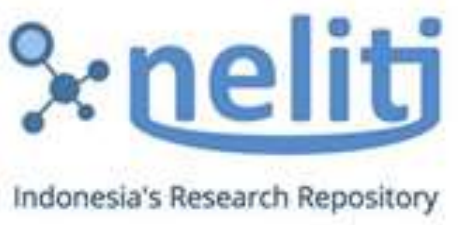

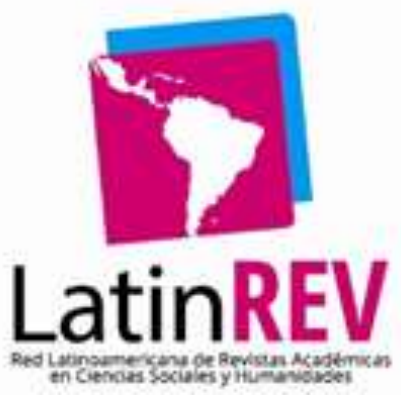

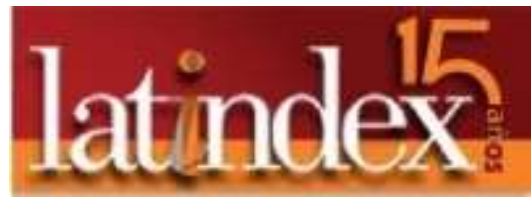

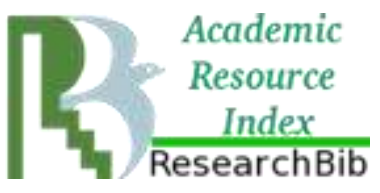

